Vol. 2, No. 1, 2019, pp. 27-32

DOI: https://doi.org/10.32698/0411

Contents lists available at Journal Redwhitepress

Journal of Counseling and Educational Technology

ISSN: 2654-8194 (Print) ISSN: 2654-9786 (Electronic)

Journal homepage: http://journal.redwhitepress.com/index.php/jcet

\title{
Self- efficacy and resilience among late adolescent
}

\author{
Nor Syakila Jaeh ${ }^{1}$, Amalia Madihie ${ }^{2}$ \\ ${ }^{12}$ Universiti Malaysia
}

\section{Article Info}

\section{Article history:}

Received Jun $20^{\text {th }}, 2019$

Revised Jul $15^{\text {th }}, 2019$

Accepted Aug 5 $5^{\text {th }}, 2019$

\section{Keyword:}

Late Adolescent

Resilience

Self- Efficacy

\begin{abstract}
The aim of this study is to examine the relationship between self- efficacy and resilience among late adolescents in the five components of resilience which are meaningfulness, perseverance, self- reliance, equanimity and existential aloneness. The number of sample was 250, aged between 18-19 year olds. Generalized Self- Efficacy (GSE) by Schwarzer and Jerusalem (1995) and Resilience Scale (RS) by Wagnild and Young (1993) were carried out. Results showed that there are significant relationships between self- efficacy and resilience in the form of meaningfulness, perseverance, self- reliance, equanimity and existential aloneness where the null hypothesis is being rejected. These findings can be used to design effective intervention to solve the client issue related with self- efficacy and resilience and promote positive behaviour such as resilience. Future research could conduct research for early adolescent, middle adolescent and late adolescent which can lead to new contribution to the research.
\end{abstract}

(C) 2019 The Authors. Published by Redwhitepress.

This is an open access article under the CC BY-NC-SA license

(https://creativecommons.org/licenses/by-nc-sa/4.0/

\section{Corresponding Author:}

Amalia Madihie,

Universiti Malaysia

Email: mamalia@unimas.my

\section{Introduction}

This research explores about self- efficacy and resilience among late adolescent at Pre- University of University Malaysia Sarawak (UNIMAS). The central focus is more to oneself and intrinsic motivation which will affect the resilience. Self- efficacy beliefs can affect the motivational and self- regulatory in several ways through the choice that is make and the course of action that take place. The effect of self- efficacy belief also can help to determine the competence on how much effort people will develop on an activity, how long people will endure the obstacles and how resilience develop in the difficult situation where the higher the self- efficacy the higher the effort, persistence and resilience (Pajares, 1996). In addition, self- efficacy is context specific and become important to individual when facing with adversity as positive self- efficacy are associate with increasing of motivation and perseverance (Bandura et al., 2001). Hence, Maclean (2004) recognized several qualities that is relate with resilience which are initiative and insight, optimism, intellectual ability, placid temperament, trust, autonomy and decision making, humor, identity, social support, education, attainment, self- esteem and self- efficacy. The main purpose of this study was to examine the relationship between selfefficacy and resilience among late adolescents in five component of resilience which are meaningfulness, perseverance, self- reliance, equanimity and existential aloneness. The research hypotheses are there is no significant relationship between self- efficacy and resilience in term of meaningfulness, perseverance, selfreliance, equanimity and existential aloneness among late adolescent. 


\section{Materials and Methods}

The research was conducted at Pre- University of Universiti Malaysia Sarawak. Overall number student of Pre- University is 735. According to Krejcie and Morgan (1970), if the number of population is 700, then the number of sample must be 248 and if the number of population is 750 , then the number of sample must be 254. So, the researcher decided to use 250 number of sample as the number is between 248 and 254 . In addition, the researcher employed simple random sampling where all individual has equal and independent chance of being chosen.

The questionnaire consists of informed consent letter, demographic background of participants, General Self- Efficacy (GSE) and Resilience Scale (RS). Instrument to measure variable self- efficacy is General SelfEfficacy Scale by Schwarzer and Jerusalem (1995) which contain of 10 items. Generalized Self- Efficacy is translated into Malay language based on the back-translation method. Instrument used to measure variable of resilience is Resilience Scale (RS) by Wagnild and Young (1993) which contain of 25 items. Resilience Scale is translated into Malay language based on back- to- back translation by (Amalia Madihie, Sidek Mohd Noah, Maznah Baba, \& Wan Marzuki Wan Jaafar, 2011). There are five components in the Resilience Scale which are Meaningfulness, Perseverance, Self- Reliance, Equanimity and Existential Aloneness.

The data was analysed by using Statistical Package for the Social Sciences (SPSS) software. In analyzing the data, the researchers used the Independent t-test and Pearson's product-moment correlation tests. The descriptive analyses were used in the data analyses in order to analyses the demographic factors.

\section{Results}

\section{Demographic Characteristic}

Demographic data were reported based on data gathered from the survey. Descriptive statistical analysis was used to identify frequencies. The frequency based on course taken for both Foundation of Life Sciences Module and Physical Sciences Module is 125 which represent $50.0 \%$ each. The frequency based on gender is $117(46.8 \%)$ of the adolescent is male and $133(53.2 \%)$ is female. The frequency based on race is 169 $(67.7 \%)$ of the adolescent is Malay, $5(2.0 \%)$ Chinese, $1(0.4 \%)$ is Indian and $75(30.0 \%)$ adolescents are come from other races. The frequency based on religion is $205(82.0 \%)$ of the adolescent is Islam, $44(17.6 \%)$ of the adolescent is Christian and $1(0.4 \%)$ of the adolescent is Hinduism. The frequency based on residency is 165 $(66.0 \%)$ of the adolescent come from urban area and $85(34.0 \%)$ come from rural area. The frequency based on region is $97(38.8 \%)$ of the adolescent is come from Peninsular, $20(8.0 \%)$ of the adolescent is come from Sabah and $133(53.2 \%)$ is come from Sarawak.

\section{Association between Self- Efficacy and Resilience- Meaningfulness among late adolescent}

A Pearson product-moment correlation coefficient was computed to assess the relationship between self- efficacy and resilience- meaningfulness among late adolescent. There was a strong, positive correlation between self- efficacy and resilience- meaningfulness among late adolescent, which was significantly $\mathrm{r}(248)=$ $.347, p=.000$. The number of $p$ value is smaller than $\alpha$ (alpha value) which is 0.05 , so the null hypothesis of there is no significant relationship between self- efficacy and resilience- meaningfulness among late adolescent is rejected. Overall, there is a strong, positive correlation between self- efficacy and resilience meaningfulness among late adolescent.

Table 1. Pearson Product Moment Correlation Coefficient of Self- Efficacy and ResilienceMeaningfulness among Late Adolescent

\begin{tabular}{lcc}
\hline Scales & $r$ & Sig. \\
\hline Self- Efficacy & .347 & .00 \\
Meaningfulness & 1.00 & .00 \\
\hline
\end{tabular}

\section{Association between Self- Efficacy and Resilience- Perseverance among Late Adolescent}

There was a strong, positive correlation between self- efficacy and resilience- perseverance among late adolescent, which was significantly $r(248)=.520, p=.000$. The number of $p$ value is smaller than $\alpha$ (alpha value) which is 0.05 , so the null hypothesis of here is no significant relationship between self- efficacy and 
resilience- perseverance among late adolescent is rejected. Overall, there is a strong, positive correlation between self- efficacy and resilience- perseverance among late adolescent.

Table 2. Pearson Product Moment Correlation Coefficient of Self- Efficacy and ResiliencePerseverance among Late Adolescent

\begin{tabular}{lcc} 
& \multicolumn{1}{c}{ Sig. } \\
\hline Scales & $r$ & .00 \\
Perseverance & .520 & .00 \\
\hline
\end{tabular}

\section{Association between Self- Efficacy and Resilience- Self- Reliance among Late Adolescent}

There was a strong, positive correlation between self- efficacy and resilience- self- reliance among late adolescent, which was significantly $r(248)=.620, p=.000$. The number of $p$ value is smaller than $\alpha$ (alpha value) which is 0.05 , so the null hypothesis of there is no significant relationship between self- efficacy and resilience- self- reliance among late adolescent is rejected. Overall, there is a strong, positive correlation between self- efficacy and resilience- self- reliance among late adolescent.

Table 3. Pearson Product Moment Correlation Coefficient of Self- Efficacy and ResilienceSelf- Reliance among late adolescent

\begin{tabular}{lcc}
\hline Scales & $r$ & Sig. \\
\hline Self- Efficacy & .620 & .00 \\
Self- Reliance & 1.00 & .00 \\
\hline
\end{tabular}

\section{Association between Self- Efficacy and Resilience- Equanimity among Late Adolescent}

There was a strong, positive correlation between self- efficacy and resilience- equanimity among late adolescent, which was significantly $\mathrm{r}(248)=.541, \mathrm{p}=.000$. The number of $\mathrm{p}$ value is smaller than $\alpha$ (alpha value) which is 0.05 , so the null hypothesis of there is no significant relationship between self- efficacy and resilience- equanimity among late adolescent is rejected. Overall, there was a strong, positive correlation between self- efficacy and resilience- equanimity among late adolescent.

Table 4. Pearson Product Moment Correlation Coefficient of Self- Efficacy and ResilienceEquanimity among Late Adolescent

\begin{tabular}{lcc}
\hline Scales & $r$ & Sig. \\
\hline Self- Efficacy & .541 & .00 \\
Equanimity & 1.00 & .00 \\
\hline
\end{tabular}

\section{Association between Self- Efficacy and Resilience- Existential Aloneness among Late} Adolescent

There was a strong, positive correlation between self- efficacy and resilience- existential aloneness among late adolescent, which was significantly $\mathrm{r}(248)=.418, \mathrm{p}=.000$. The number of $\mathrm{p}$ value is smaller than $\alpha$ (alpha value) which is 0.05 , so the null hypothesis of there is no significant relationship between self- efficacy and resilience- existential aloneness among late adolescent is rejected. Overall, there is a strong, positive correlation between self- efficacy and resilience- existential aloneness among late adolescent.

Table 5. Pearson Product Moment Correlation Coefficient of Self- Efficacy and ResilienceExistential Aloneness among Late Adolescent

\begin{tabular}{ccc}
\hline Scales & $\boldsymbol{r}$ & Sig. \\
\hline Self- Efficacy & .418 & .00 \\
Existential Aloneness & 1.00 & .00 \\
\hline
\end{tabular}

\section{Discussion}

The research show that there is a statistically significant relationship between self- efficacy and resilience- meaningfulness among late adolescent. This result supported by Shek and colleagues (2003) which perceived meaning in life was positive associate with self- esteem and self- efficacy among adolescent with economic disadvantage. 
There is a statistically significant relationship between self- efficacy and resilience- perseverance among late adolescent. This result supported by Schunk and DiBenedetto (2016) where effort, perseverance and selfregulation are three dimensions of self-efficacy which effort and perseverance can bring success for students in their tackling with existing barriers, enhance their performance in confrontation with difficulties, improve their sense of self-regulation, and help them flourish their potential self-efficacy.

There is a statistically significant relationship between self- efficacy and resilience- self- reliance among late adolescent. This result supported by Edward, Welch and Chater (2009) where self- efficacy and selfreliance are important factor that can contribute to a sense of resilience.

There is a statistically significant relationship between self- efficacy and resilience- equanimity among late adolescent. This result is supported by Stagman-Tyrer (2014) where self-efficacy enables the nurse leader to build resilience through equanimity, optimism, and perseverance.

There is a statistically significant relationship between self- efficacy and resilience- existential aloneness among late adolescent. The researcher found no direct studies that confirm or deny the results. However, Hamill (2003) stated that self- efficacy is an important trait in the development of competence when facing adversity.

Overall, the research findings of self- efficacy have strong positive correlation with resilience among late adolescent in the form of meaningfulness, perseverance, self- reliance, equanimity and existential aloneness already support the literature by Bandura (1994), which self- efficacy can affect resilience to adversity. The research findings also supported the past research in the literature review by (Cassidy, 2015; Sagone and Caroli, 2013; Keye and Pidgeon, 2013; Sagone and De Caroli, 2016; Narayanan and Onn, 2016). The research finding also supported the literature by Schwarzer and Warner (2013), which if the self- efficacy belief has been activated, then it can promote the resilience. The research findings also supported the past research finding by Svence and Greaves (2013) where the higher level of general self- efficacy is related to the higher level of resources which are resilience and wisdom.

\section{Results and Discussion}

Table 6 Summary of the Result

\begin{tabular}{|c|c|c|c|}
\hline No. & Hypotheses & SPSS Method & Result \\
\hline 1 & $\begin{array}{l}\mathrm{H}_{\mathrm{o}} 1 \text { : There is no significant relationship between } \\
\text { self- efficacy and resilience- meaningfulness } \\
\text { among late adolescent }\end{array}$ & Pearson correlation & $\begin{array}{c}\text { Rejected } \\
p=.000<\alpha\end{array}$ \\
\hline 2 & $\begin{array}{l}\mathrm{H}_{\mathrm{o}} 2 \text { : There is no significant relationship between } \\
\text { self- efficacy and resilience- perseverance among } \\
\text { late adolescent }\end{array}$ & Pearson correlation & $\begin{array}{c}\text { Rejected } \\
p=.000<\alpha\end{array}$ \\
\hline 3 & $\begin{array}{l}\mathrm{H}_{\mathrm{o}} 3 \text { : There is no significant relationship between } \\
\text { self- efficacy and resilience- self- reliance among } \\
\text { late adolescent }\end{array}$ & Pearson correlation & $\begin{array}{c}\text { Rejected } \\
p=.000<\alpha\end{array}$ \\
\hline 4 & $\begin{array}{l}\mathrm{H}_{\mathrm{o}} 4 \text { : There is no significant relationship between } \\
\text { self- efficacy and resilience- equanimity among } \\
\text { late adolescent }\end{array}$ & Pearson correlation & $\begin{array}{c}\text { Rejected } \\
p=.000<\alpha\end{array}$ \\
\hline
\end{tabular}

The adolescent's intelligence can be the contribution factors of the research finding where there is significant relationship between resilience in the form of meaningfulness, perseverance, self- reliance, equanimity and existential aloneness among late adolescents of Pre- University of Universiti Malaysia Sarawak. This is supported by Shean (2015) where high intelligence is generally associated with resilience. High intelligence can be related with the ability to think better which can lead to resilience. This is supported by Bas oğ ul and Özgür (2016) where the emotional intelligence influences the individual to recognize, understand and manage emotion which can help to efficiently cope with daily demands, challenges and pressure. So, the adolescent with high emotional intelligence will be able to cope with the adversity and able to bounce back due to they able to efficiently manage their emotion.

\section{Conclusion}

Findings from the current research has been found to be consistent with the several related studies on self- efficacy and resilience. Significant of this study is it will be useful to educators, counsellors, psychologists 
and researcher in order to develop approaches that will help to improve the students' academic excellence. As the counsellor understand the client's better, then it will help the counsellor to find the best approach or solution to solve the client issue related with self- efficacy and resilience. These findings can be used to design effective intervention to promote resilience. As the current research is conducting research on late adolescent, so it is advisable for future researchers to conduct research for early adolescent, middle adolescent and late adolescent which can lead to new contribution to the research. In the current research, most number of samples are consisting of Malay and Islam religion where future researchers should involve more participant that come from other races and other religion in order to contribute to good and firm research findings.

\section{References}

Amalia Madihie, Sidek Mohd Noah, Maznah Baba, \& Wan Marzuki Wan Jaafar. (2011). Back-to-

Back Translation for the Resilience Scale (25 items) from English language to Malay Language. Retrieved from https://www.researchgate.net/publication/291352254 Back-to-

Back Translation for the Resilience Scale 25 items from English language to Malay Language

Bandura, A. (1994). Self-efficacy. In V. S. Ramachaudran (Ed.), Encyclopedia of Human Behavior, 4, 71- 81.

Bandura, A., Barbaranelli, C., Caprara, G. V., \& Pastorelli, C. (2001). Self- efficacy belief as shapers of children's aspirations can career trajectories. Child Development, 72, 187- 206.

Başoğul, C., \& Özgür, G. (2016). Role of emotional intelligence in conflict management strategies of nurse. Asian Nursing Research, 10(2016), 228- 233.

Cassidy, S. (2015). Resilience Building in Students: The role of Academic Self- Efficacy. Frontiers in Psychology, 6(1781), 1- 14 .

Edward, K., Welch, A., \& Chater, K. (2009). The phenomenon of resilience as described by adults who have experienced mental illness. Journal of Advanced Nursing, 65(3), 587-595.

Hamill, S. K. (2003). Resilience and self- efficacy: The importance of self- efficacy beliefs and coping mechanism in resilient adolescents. Colgate University Journal of the Sciences, 35, 115- 146.

Keye. M. D., \& Pidgeon, A. M. (2013). An investigation of the relationship between, resilience, mindfulness, and academic self- efficacy. Open Journal of Social Sciences, 1(6), 1-4.

Krejcie, R. V., \& Morgan, D. W. (1970). Determining sample size for research activities. Educational and Psychological Measurement, 30, 607- 610.

Maclean, K. (2004). Resilience: What it is and how children and young people can be helped to develop it. Online Journal of the International Child and Youth Care Network, 62. Retrieved from http://www.cycnet.org/cyc-online/cycol-0304-resilience.html

Narayanan, S. S., \& Onn, A. C. W. (2016). The influence of perceived social support and self- efficacy on resilience among first year Malaysian students. Kajian Malaysia, 34(2), 1- 23. Retrieved from http://dx.doi.org/10.21315/km2016.34.2.1

Pajares, F. (1996). Current directions in self- efficacy research. In M. Maehr \& P. R. Pintrich (Eds.), Advances in motivation and achievement, 10, 1- 49.

Pajares, F. (1996). Self- efficacy beliefs in academic settings. Review of Educational Research, 66, 543- 578.

Sagone, E., \& De Caroli, M. E. (2013). Relationship between resilience, self- efficacy, and thinking styles in Italian middle adolescents. Procedia- Social and Behavioral Sciences, 92 (2013), 838- 845.

Sagone, E., \& De Caroli, M. E. (2016). "Yes ... I can": Psychological resilience and self- efficacy in adolescents. International Journal of Developmental and Educational Psychology, 1(1), 141- 148.

Schunk, D. H., \& DiBenedetto, M. K. (2016). Self-efficacy Theory in Education. In Handbook of Motivation at School, 3, 34- 54.

Schwarzer, R., \& Jerusalem, M. (1995). Generalized Self- Efficacy scale. In J. Weinman, S. Wright, \& M. Johnston, Measure in health psychology: A user's portfolio. Causal and control beliefs, 35- 37.

Schwarzer, R., \& Warner, L. M. (2013). Perceived self- efficacy and its relationship to relationship. In S. Prince-Embury \& D. H. Saklofske (Eds.), The Springer series on human exceptionality: Resilience in children, adolescents, and adults: Translating research into practice, 139- 150.

Shean, M. (2015). Current theories relating to resilience and young people: A literature review. Melbourne: Victorian Health Promotion Foundation.

Shek, D. T. L., Lam, M. C., Lam, C. M., Tang, V., \& Tsoi, K. W. (2003). Meaning of life and adjustment among Chinese adolescents with and without economic disadvantage. In T. A. Prester (Ed.), Psychology of adolescents. New York: Nova Science Publishers.

Stagman-Tyrer, D. (2014). Resiliency and the nurse leader: The importance of equanimity, optimism and perseverance. Nursing Management, 45(6), 46- 50. 
Svence, G., \& Greaves, V. (2013). Factors of resilience, wisdom and self- efficacy as positive resources of leaders in sample of Latvian business managers. Problems of Psychology in the $21^{\text {st }}$ Century, 5, 96- 108.

Wagnild, G. M, \& Young, H. M (1993). Development and psychometric evaluation of the Resilience scale. Journal of Nursing Measurement, 1, 165- 178. 